\title{
BIM 技术在市政工程造价管理中的应用
}

\author{
潘炳然 \\ 烟台聚信人力资源管理有限公司，山东烟台 264001
}

\begin{abstract}
[摘要]在整个市政工程项目的建造和施工完成之后, 往往会出现建造成本费用超支的现象。这对于整个市政工程项目来说会 严重的影响工程项目的经济效益, 因此精确计算工程项目的成本费用, 对整个市政工程项目的成本管理和控制有着非常重要 的影响。在市政工程项目的施工建设环节, 由于对工程项目的施工机械设备、建筑材料、人力资源等方面的估计不准确, 导 致了整个市政工程项目的成本在实际花销和预算上往往有很大的差异。在市政工程项目的管理中有效的使用 BIM 技术, 可以 大大有助于市政工程项目各方面管理的工作。对市政工程在竣工验收的时候的审计以及在合理控制工程项目总投资方面发挥 了极为关键和重要的作用。市政工程项目的工程结算的质量和水平直接关系到对应施工方和建设方的切身利益和工程项目投 资收益的提升。因此，提高工程项目的造价结算的有关人员的业务水平和专业素质是非常重要的。
\end{abstract}

[关键词]BIM 技术; 市政工程; 项目造价

DOI：10.33142/aem.v2i6.2400 中图分类号: TU17;TU99 文献标识码: A

\section{Application of BIM Technology in Municipal Engineering Cost Management}

\author{
PAN Bingran
}

Yantai Juxin Human Resource Management Co., Ltd., Yantai, Shandong, 264001, China

\begin{abstract}
After construction of the whole municipal engineering project is completed, the phenomenon of construction cost overrun often appears. This will seriously affect the economic benefits for the whole municipal engineering project, so the accurate calculation of the cost of project has a very important impact on the cost management and control of the whole municipal engineering project. In the construction process of municipal engineering project, due to the inaccurate estimation of construction machinery and equipment, building materials, human resources and other aspects of the project, the cost of the whole municipal engineering project often has a great difference in actual cost and budget. In the management of municipal engineering projects, the effective use of BIM Technology can greatly contribute to the management of municipal engineering projects in all aspects. It plays a key and important role in the audit of municipal engineering in the final acceptance and reasonable control of the total investment of project. The quality and level of project settlement of municipal engineering project is directly related to the vital interests of the corresponding construction party and the construction party and the improvement of the investment income of project. Therefore, it is very important to improve the professional level and quality of the relevant personnel of project cost settlement.
\end{abstract}

Keywords: BIM Technology; municipal engineering; project cost

引言

市政工程项目的建造施工对于城市的发展来说是非常重要的, 所以说必须要确保工程项目建造施工的成本管理和 控制工作的高质量开展, 确保工程项目的经济效益和社会效益的实现是至关重要的。当然这也是整个工程项目建设水 平不断提高的基础和前提, 也是进一步促进人们生活环境以及城市进步的重要因素。这一类型的工程项目的建造施工 往往有一定的复杂性, 因此, 许多工程项目在施工管理阶段采用了先进的 BIM 技术, 不仅可以保证工程项目的建造施 工的高效以及治理, 也可以确保工程项目成本管理的水平和质量。这一技术依赖于互联网技术和信息技术，可以大幅 度的降低工程项目的成本控制难度。同时它大大提高了管理成本的精度, 这是非常有益的、更是非常必要的。

1 市政项目以及 BIM 技术综述

目前国内的市政工程项目主要是建造基本的设施, 为城市和村庄当中的居民提供生活的方便。对于市政工程项目 来说, 有些项目是向使用者进行收费的, 例如城市的电信服务、电力、燃气、自来水等等。有些是免费为人民提供的, 例如, 城市的绿化, 给排水设施、道路等等。不管是免费还收费这些都是能够有效帮助人们改善生活质量的市政工程 项目。在工程项目的施工建设环节应用 BIM 技术, 对于建筑施工的行业来说很重要, 使用这样的工具可以通过计算机 系统来创建一个立体的三维模型, 然后帮助有关施工人员和管理人员更好地进行工程项目的施工和管理。目前, 这种 
技术已经广泛的用于市政工程项目当中，同时也显示了其强大的积极效果和促进功能，因此，将这一技术纳入到工程 项目成本管理和控制可以有效地提高工程项目的管理和控制水平。BIM 技术可以在工程项目的全面生命周期内发挥作用, 并具有很高的可靠性，这不仅保证了市政工程项目建设的质量和水平，而且还可以有效的控制成本 ${ }^{[1]}$ 。

\section{2 市政工程造价管理的现状分析}

\section{1 市政工程造价得不到全程控制}

随着我国经济社会的发展, 中国的城市建设实现了大跨越, 工程项目的有关产业在这个背景下进行了迅速的发展。 虽然中国城市当中的工程项目建设规模逐年增长, 但不可否认的是市政工程项目的现代化总体来说进展还是十分缓慢 的, 特别是在市政工程项目建设的成本管控方面。市政工程项目的建设单位过于注重提高项目的经济效益, 往往会忽 视工程项目的成本管理系统的建设, 忽视了整个市政工程项目的管理制度的完善。此外, 市政工程项目的建设涉及多 个部门以及多个环节, 但往往不同的部门和部门之间的存在着一定的沟通障碍, 交流和互动不足, 导致工程项目的规 划建设缺乏统一性。因此, 市政工程项目的施工单位、项目单位以及监督和管理部门等有关主体必须要肩负起责任, 确保这些单位的工作人员具备较高的综合素质和专业能力, 在岗前得到适当的、科学的技能培训, 不能只专注于自己 或者自己部门的利益, 必须要以整个市政工程项目的建设为先, 并独立自主又协作配合地开展工作, 确保工程项目的 建造质量和水平。

\section{2 市政工程造价的数据分析不全面}

在对工程项目的施工建设的有关数据资料进行了多次的比较和精心计算之后, 有广场项目的成本费用的数据才可 以更好地确认, 成本造价是很重要的, 必须要通过大量的实际数据作为基础, 而不是偶然的假设或大概的估计。在正 常情况下, 市政工程项目的成本费用的计算主要来自以下方面, 即工程项目的概算、预算以及结算。这三个不同阶段 中的每一个内容的重点和要求都是有着很大的差别的, 需要的信息和数据的相关性也不同。如果没有做好有关环节的 计算的话, 那么这将导致在每个阶段对汇编数据产生影响, 导致不准确的数据信息, 这将严重的影响到市政工程项目 的建设同时也将需要消耗大量的工作时间以及人力资源进行反复的计算, 这将增加工程项目的施工工期以及成本费用 的损耗 ${ }^{[3]}$ 。

\section{3 数据实现不了共享}

在市政工程项目的建设施工的过程中, 每个市政过程项目都有一定的施工的隐患和风险。一个关键的工作内容是 必须要做好相关风险隐患的管理和控制, 与此同时过程项目的施工建设的成本信息也会存在一定的延迟，无法实现实 时动态的传送和更新, 这往往会导致市政工程项目的预算和不同阶段的实际建设成本费用可能存在一些差距和不相。 如果工程项目的建设方完全盲目地按照自己的愿望进行市政工程项目的建设和施工, 并出现了这种数据信息的传输不 畅通以及无法及时更新的问题, 都会导致工程项目建设施工的质量和安全威胁, 这些问题的根本原因是没有积极的通 过 BIM 的平台进行信息的沟通和协调。也就是说 BIM 技术可以有效地解决这一类问题。

\section{4 工程造价数据缺乏时效性}

在市政工程项目的成本管理和控制的过程中, 往往会受到各种各样的负面因素的不利影响。例如, 建筑原材料的 价格往往会因市场价格波动而发生着不断的变化, 因此在这方面, 经常会出现成本预算和实际的建筑材料成本花费的 不相符的问题, 进一步影响了整个工程项目的造价管理。此外一些市政工程项目的成本消耗以及费用管理没有办法进 行实时动态的更新, 相关的数据的更新不同于实际的市场价格变化的及时性, 目前, 我国大多数市政工程公司通常利 用国家提供的相关行业数据进行工程项目建造总体成本的评估和更新, 而这些数据的更新是比较缓慢的, 无法及时的、 准确地反映当前建筑市场的实际情况, 因此所获得的成本数据往往存在一些错误和不准确的问题 ${ }^{[4]}$ 。

\section{BIM 技术在市政工程造价管理中具体应用}

\section{1 市政工程设计阶段的造价管理}

在市政工程项目建设施工的成本管理和控制的工作中, 工程项目的设计阶段的成本管理是最根本和最基础的工作 环节, 也是影响到整个工程项目的成本管理的核心内容。市政工程项目的建设在传统方法上计算和评价工程项目建设 成本的环节存在着诸多问题, 不可能进行非常精确的成本费用的计算, 这严重影响了市政工程项目的成本管理和控制, 而是用了 BIM 技术就可以有效的解决这一问题。 


\section{2 市政工程决策阶段的造价管理}

不管是什么样的市政工程项目, 投资决策的过程是非常重要, 直接关系到工程项目总成本投入, 如果投资决策出 现了问题, 将造成有关方面严重的经济损失, 从而大大降低市政工程项目的质量以及效益, 也会进一步影响有关部门 的市场竞争优势。因此, 市政当局在作出工程项目投资和施工决策时应更加重视决策阶段的科学合理的研判, 对该工 程项目的投资决策应根据实际情况进行深入的分析和评估。

\section{3 市政工程施工阶段的造价管理}

BIM 技术在市政工程项目建设阶段的应用可以建立适当的工程模型, 并合理、高效的使用建筑材料、机械设备以及 人力资源, 根据相关数据, 有效控制市政工程项目建设的总体成本。

\section{结束语}

总而言之, BIM 技术的运用能够显著的提高市政项目造价管控的品质, 减少工程项目的成本损耗, 能够更好的提升 市政项目造价管控的水准，提高其经济社会效益。

\section{[参考文献]}

[1]杨荣. BIM 技术在市政工程造价管理中的运用 [J].建材与装饰, 2018 (52) : 136-137.

[2]马利英,宋开功. BIM 技术在市政工程造价管理中的应用分析 [J].山东工业技术, 2019(07): 110 .

[3]王文敏. 基于 BIM 技术的市政工程造价管理研究 [J]. 工程建设与设计,2019(07): 321-323.

[4] 吴秀玉. BIM 技术在市政工程造价管理中的应用分析 [J]. 科技经济导刊, 2019, 27 (13) : 53-52.

[5]孔凡达. BIM 技术在市政工程造价管理中的应用分析 [J]. 绿色环保建材, 2019 (08) : 164.

作者简介: 潘炳然 (1989.2-), 男, 山东烟台人, 汉族, 大学本科学历, 助理工程师, 研究方向为市政工程管理方向。 